\title{
Coexistence of linear IgA bullous dermatosis and systemic lupus erythematosus: a case report
}

Peiyu Wang ${ }^{1}$ and Guang-Wen Yin ${ }^{1}$

${ }^{1}$ Zhengzhou University First Affiliated Hospital

July 7,2021

\section{Hosted file}

case_report (1).docx available at https://authorea.com/users/424255/articles/529383coexistence-of-linear-iga-bullous-dermatosis-and-systemic-lupus-erythematosus-a-casereport

\section{Hosted file}

Figures.docx available at https://authorea.com/users/424255/articles/529383-coexistence-oflinear-iga-bullous-dermatosis-and-systemic-lupus-erythematosus-a-case-report 